\title{
Erratum to "Conformational Dynamics of Sclerostin-LRP6 Complex Analyzed by HDX-MS" [Biomol.Ther. 29 (2021) 527-535]
}

\author{
Yejin Jeong', Jinuk Kim², Hee-Jung $\mathrm{Choi}^{2, *}$ and Ka Young Chung ${ }^{1, *}$ \\ ${ }^{1}$ School of Pharmacy, Sungkyunkwan University, Suwon 16419, \\ ${ }^{2}$ Department of Biological Sciences, Seoul National University, Seoul 08826, Republic of Korea
}

The authors request to correct the spelling of the author Yejin Jeong, which was incorrectly given as Yejing Jeong.

\section{Open Access https://doi.org/10.4062/biomolther.2022.002}

This is an Open Access article distributed under the terms of the Creative Commons Attribution Non-Commercial License (http://creativecommons.org/licenses/by-nc/4.0/) which permits unrestricted non-commercial use, distribution, and reproduction in any medium, provided the original work is properly cited.
DOI of original article : https://doi.org/10.4062/biomolther.2020.234

${ }^{*}$ Corresponding Authors

E-mail: choihj@snu.ac.kr (Choi HJ), kychung2@skku.edu (Chung KY) Tel: +82-2-880-6605 (Choi HJ), +82-31-290-7787 (Chung KY) Fax: +82-2-872-1993 (Choi HJ), +82-31-292-8800 (Chung KY) 